\title{
Establishing and Evaluating Clinical Pharmacy Training Program in China Pharmaceutical University
}

\author{
Jiaqi $\mathrm{Li}^{1,2}$, Changqing Yang ${ }^{2, *}$, Madiha ${ }^{2,3}$ \\ ${ }^{1}$ Department of Pharmacy, Nanjing Drum Tower Hospital, The Affiliated Hospital of Nanjing University Medical School, Jiangsu, CHINA. \\ ${ }^{2}$ Department of Clinical Pharmacy, School of Basic Medicine and Clinical Pharmacy, China Pharmaceutical University, Nanjing, Jiangsu, \\ CHINA. \\ ${ }^{3}$ Hamdard Institute of Pharmaceutical Sciences, Hamdard University, Islamabad Campus, PAKISTAN.
}

\begin{abstract}
Background: Clinical pharmacy training is to help students master the skills of clinical pharmacy services and increase students' confidence in their ability to perform clinical roles effectively. Objective: This study aimed to introduce and evaluate clinical pharmacy training program in China Pharmaceutical University for bachelor's degree students majored in clinical pharmacy. Method: Clinical pharmacy training in China Pharmaceutical University comprises various modules. In this article we have discussed the establishment and evaluation of following four main training modules: 1) physical assessment, 2) cardiopulmonary resuscitation, 3) medication information service and 4) patient education service. And students who participated in this training were asked to complete questionnaires to determine their general perception regarding clinical pharmacy training program and to assess their satisfaction, knowledge and skills at the end of this program. Results: Most of the students ( $>90 \%$ ) showed a keen interest in clinical training course. They believed that clinical pharmacy training could promote the integration of theory with practice, increase interest in learning and help them to understand the theoretical knowledge and clinical pharmacy services more easily. Students have also showed high satisfaction from this training in four mentioned services. Satisfaction scores (on the scale of 5) for physical assessment training, cardiopulmonary resuscitation training, medication information service training and patient medication were $4.22(S D=0.78), 4.75$ $(S D=0.55), 4.51(S D=0.66)$ and $4.81(S D=0.47)$ respectively. Students' confidence in providing clinical pharmacy services was significant improved after training. Conclusion: Clinical pharmacy training can increase students' interest in learning and improve their practical abilities. It is a feasible way of increasing students' knowledge and skills.
\end{abstract}

Key words: Clinical pharmacy training, Evaluation, Clinical pharmacy students, China Pharmaceutical University.

\section{INTRODUCTION}

Pharmaceutical education is now oriented more towards problem solving and providing patient care. ${ }^{1}$ According to the standards for Pharm-D degree program (2007) by the Accreditation Council for Pharmacy Education (ACPE), introductory pharmacy practice experiences (IPPEs) should not be less than $5 \%$ of the curriculum or a minimum of 300 h. $^{2}$ Furthermore, ACPE Standards (2016) suggested that a college or school may choose structured simulation which is defined as an activity or event replicating pharmacy practice as part of the overall IPPE to meet program goals and objectives and it can account up to $60 \mathrm{~h}$ of the $300 \mathrm{~h}^{3}$ ACPE also stated that simulation may include use of high-fidelity manikins, standardized patients, role play and computer-based simulations. ${ }^{4}$

Role of simulations in health care education and practice is already estabished. ${ }^{5-7}$ Many of the pharmacy colleges or schools have conducted simulation training programs to improve pharmacy students' competency
Submission Date: 11-05-2018; Revision Date: 14-08-2018; Accepted Date: 23-10-2018

DOI: 10.5530/ijper.53.1.10 Correspondence: Dr. Changqing Yang, Professor, Department of Clinical Pharmacy, School of Basic Medicine and Clinical Pharmacy, China Pharmaceutical University, Nanjing, Jiangsu, CHINA. Phone no: 86-25-86185447 E-mail: ycq0315@yahoo.com

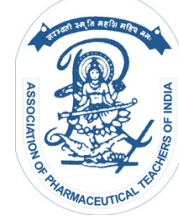

www.ijper.org 
of providing clinical pharmacy services. ${ }^{8}-10$ A survey showed that seventy four colleges and schools of pharmacy out of eighty eight in USA were using simulationbased teaching where it was mostly employed for patient care laboratory courses and patient/physical assessments. ${ }^{11}$ For example, The University of Missouri-Kansas City School of Pharmacy used high-fidelity patient simulation for IPPE. ${ }^{12}$ Northeastern University School of Pharmacy established a simulated hospital pharmacy for pharmaceutical care skills course. ${ }^{13}$ In Japan, pharmacy education had transformed to a 6 -years program focusing on pharmaceutical care in $2006 .{ }^{14}$ To adapt this new educational model, some of the pharmacy schools had devised clinical training modules. ${ }^{15}$ Kyushu University of Health and Welfare's School of Pharmaceutical Sciences had used simulators to teach vital-signs monitoring to all third-year pharmacy students. ${ }^{16}$

In 1989, West China School of pharmacy (now as Center of Medical Sciences, Sichuan University) had developed first BS Clinical pharmacy degree. ${ }^{17}$ But the progress in field of clinical pharmacy was abolished until the Ministry of Education of China allowed China pharmaceutical university (CPU) to reestablish its 5 yrs BS clinical pharmacy program in 2006. With the growing needs of pharmacists, China has also prioritized clinical pharmacy education. Until 2016, there were 35 universities or colleges offering clinical pharmacy education.

Development of practical abilities plays increasingly important role in pharmacy education. There were already some schools of pharmacy in China using simulation model for pharmacy practice ${ }^{18-20}$ and most of them had established simulated pharmacies, where students mostly simulate the drug dispensing process and no particular clinical skills were to be improved. In order to transform traditional pharmacy practice to a patient care service and lay a foundation of improved practical oriented clinical pharmacy education, CPU had designed a clinical pharmacy training program, which not only includes a simulated dispensing practice but also encompass simulated clinical practice. In these training, problem-based learning (PBL), role-play and high-fidelity patient simulations were used.

The objective of this study was to describe how clinical pharmacy training program was designed and implemented in CPU. Also, some surveys were carried out at the end of this training to evaluate students' perception, understanding and knowledge.

\section{MATERIALS AND METHODS}

Training courses were designed and conducted in Clinical Pharmacy Training Center in CPU, China, which had a simulated pharmacy, simulated ward, pharmacy clinic and electronic room. Clinical pharmacy training program contained several modules including traditional pharmacy practice, physical assessment, cardiopulmonary resuscitation (CPR), medication information (MI) service, patient education services, pharmaceutical care for COPD patient, pharmacy intravenous admixture services (PIVAS) and therapeutic drug monitoring (TDM) service (Table 1). The training was offered in $8^{\text {th }}$ semester to fourth-year students (since 2015) majored in clinical pharmacy. It comprised of 52 contact hours and students attended the training a half day each week, each training session included approximately 15 students. In this article we had discussed and evaluated four main clinical pharmacy training modules such as physical assessment, CPR, MI service and patient education services.

\section{Physical Assessment Training}

Physical assessment is an effective method to evaluate the body and its function. The use of physical assessment is an important part of drug therapy and adverse drug reactions monitoring. Training module of physical assessment took 4 contact hours and was held in simulated ward with High Fidelity Patient Simulator "Stan ${ }^{\circledR}$ ". Firstly, the professor showed students how to do physical assessment by High Fidelity Patient Simulator "Stan ${ }^{\circledR}$ ", e.g. the fundamentals of blood pressure assessment, the use of stethoscope. Then students practiced the measurement of blood pressure, listen the heart sound, percuss the abdomen under the guidance of the professor.

\section{CPR Training}

$\mathrm{CPR}$ is an emergency procedure, which consists of basic life support, advanced cardiovascular life support and post-cardiac arrest care for sudden cardiac arrest and death. CPR training was delivered in 3 parts: delivering the fundamental knowledge of CPR, scenario simulation and CPR practice. Fundamental knowledge focused the information regarding the skill of executing $\mathrm{CPR}$ process and common drugs for post-cardiac arrest patients based on American Heart Association Guidelines (2010) for Cardiopulmonary Resuscitation and Emergency Cardiovascular Care and Chinese Cardiopulmonary Resuscitation Expert Consensus (2011). ${ }^{21,22}$ In scenario simulation, High Fidelity Patient Simulator "Stan ${ }^{\circledR}$ " was used to simulate CPR after ventricular fibrillation, including defibrillation and drug treatment. Students observed the changes of vital signs through the High-Fidelity Patient Simulator "Stan ${ }^{\circledR}$ " (Figure 1). The simulated ward also provided two CPR simulators for students to practice. Moreover, teachers checked the students' performance during practice. 


\begin{tabular}{|c|c|}
\hline Items & Contents and Learning Objectives \\
\hline Physical assessment & $\begin{array}{l}\text { a) Master the monitoring of vital signs by using High Fidelity Patient Simulator "Stan®". } \\
\text { b) Develop familiarity with physiological characteristics, signs and symptoms of common } \\
\text { diseases using High Fidelity Patient Simulator "Stan®". } \\
\text { c) Observe ADR using High Fidelity Patient Simulator "Stan®". }\end{array}$ \\
\hline CPR & $\begin{array}{l}\text { a) Master the skills of CPR using ECS and High Fidelity Patient Simulator "Stan®" for BLS, } \\
\text { ACLS and PLS. }\end{array}$ \\
\hline Medication information service & $\begin{array}{l}\text { a) Master the medication information service skills for Collecting, Sorting, Processing, } \\
\text { Storage and Delivery of evidence based medication information. }\end{array}$ \\
\hline Patient education service & $\begin{array}{l}\text { a) Master the use of Problem Oriented Medical Record and SOAP. } \\
\text { b) Master the patient counseling skills using clinical cases of hypertension, diabetes and } \\
\text { hyperlipidemia. }\end{array}$ \\
\hline Pharmaceutical care for COPD patient & $\begin{array}{l}\text { a) Develop familiarity with signs and symptoms of COPD using High Fidelity Patient } \\
\text { Simulator "Stan®". } \\
\text { b) Understand the impact of drugs on COPD using High Fidelity Patient Simulator "Stan®". }\end{array}$ \\
\hline Pharmacy practice & $\begin{array}{l}\text { a) Understanding the infrastructure and function of pharmacy. } \\
\text { b) Develop familiarity with the classification and placement of drugs, the content of } \\
\text { drug package inserts, drug dosage forms, etc. } \\
\text { c) Master the methods and skills of prescription dispensing. } \\
\text { d) Master different medication error management skills. } \\
\text { e) Understanding the use of narcotic drugs and their management. }\end{array}$ \\
\hline PIVAS & $\begin{array}{l}\text { a) Be familiar with the structure and function of PIVAS. } \\
\text { b) Be familiar the standard for quality management of PIVAS. } \\
\text { c) Master the skills of dispensing intravenous admixture of antimicrobials and antineoplastic } \\
\text { agents. }\end{array}$ \\
\hline TDM service & $\begin{array}{l}\text { a) To familiarize with the assay methods for TDM of various drugs. } \\
\text { b) Master the counseling process and skills related to TDM. }\end{array}$ \\
\hline
\end{tabular}

$A D R=$ adverse drug reaction; $C P R=$ cardiopulmonary resuscitation; $B L S=$ basic life support; $A C L S=$ advanced cardiovascular life support; $P L S=$ prolonged life support; $E C S=$ emergency care simulator; $C O P D=$ chronic obstructive pulmonary disease; PIVAS=pharmacy intravenous admixture services; TDM=therapeutic drug monitoring

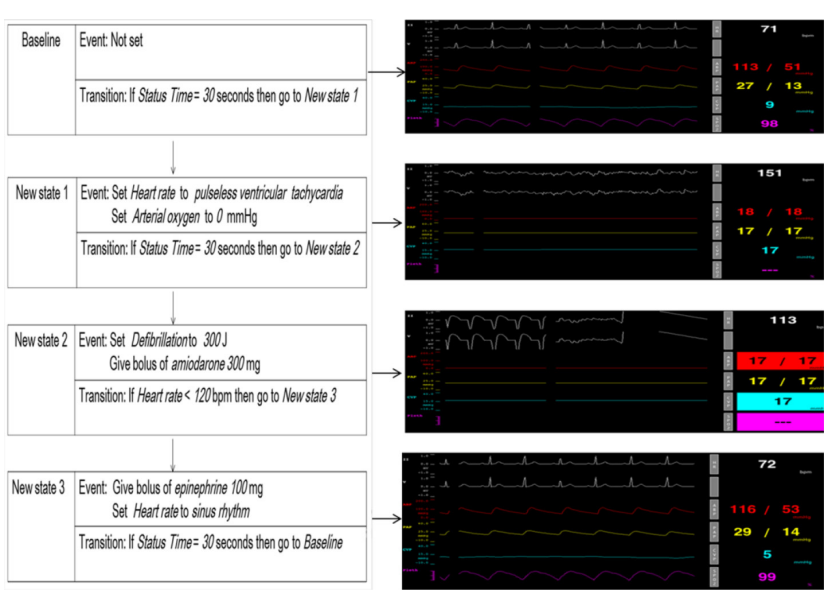

Figure 1: The Program of CPR Scenario Simulation by High-Fidelity Patient Simulator "Stan®".

Figure legends: Figure 1 shows CPR Scenario Simulation by High Fidelity Patient Simulator "Stan®". The words in the left of the figure means the scenario we programmed, the process of CPR is simulated by the connection of "state". The right part of the figure represents "patient's" vital signs in each "state".

\section{Medication Information Service Training}

Provision of accurate, required and reliable $\mathrm{MI}$ is an essential part of hospital pharmacy. Regulations of Pharmacy Administration in the Medical Institution
(January 2011) stated that medical institutions should establish MI center to provide drug information to the patients and general public. ${ }^{23}$ But it required appropriate knowledge and skills to gather and communicate this information effectively. The module of MI service training was introduced to develop and improve these skills among students. The session was held in electronic classroom in two parts. Firstly, the teacher delivered a theoretical lecture to the students regarding collection, sorting, processing, storage and delivery of MI. Then, students practiced it in form of groups. Four students as a group, searched for the information asked by medical staff and patients such as drug adverse reaction, selection of alternative therapies, drug interaction and therapeutic regimen, etc. with computers or reference books within 3 hour (Figure 2).

\section{Patient Education Service Training}

In 2011, the International Pharmaceutical Federation and World Health Organization suggested that the goal of pharmacy practice was to provide a rational choice of drugs or medical products for patients and society, which required pharmacists not only to have professional knowledge, but also to have some communication skills. ${ }^{24}$ Prescription Administrative Policy (February 


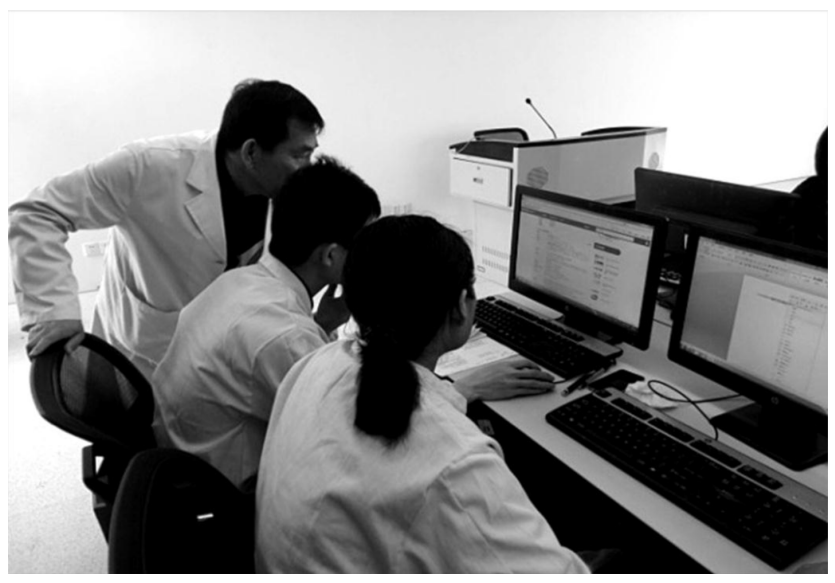

Figure 2: Medication Information Service Training.

Figure legends: Figure 2 shows the professor is instructing the students to search the medication information.

2007) and Regulations of Pharmacy Administration in the Medical Institution (January 2011) stated that pharmacists should provide patient education service. ${ }^{23,25}$

Like MI training, patient education service training had both the theoretical knowledge teaching and simulation practice. The teacher briefly introduced students with the types, requisites and content of patient's education and situations requiring attention. Then, students roleplayed the process of providing patient education. In this training, the scenarios were provided to the students a week in advance. Students were guided to work as a pair, one acted as clinical pharmacist and the other one acted as a patient. Each group had 10-20 min to play the scenario they were assigned. Teachers evaluated the student's performance who educated the patient as a clinical pharmacist. For example, a role-play scenario was as follows: Mrs. Wang, female, 56-years old, height $155 \mathrm{~cm}$, weight $71 \mathrm{~kg}$. She was diagnosed with type 2 diabetes at an age of 36 years. Results of laboratory test: FPG 7.28mmol/L, PPG $12.39 \mathrm{mmol} / \mathrm{L}, \mathrm{HbA} 1 \mathrm{C} 4.7$ to $5.9 \%$. Medication history: Diamicron (gliclazide) 30-60 $\mathrm{mg}$ for 10 years. She complains of hunger, taking snacks abruptly and nervousness. Her new prescriptions were: (1) Basen (voglibose, $0.2 \mathrm{mg} /$ tablet) 1T TID, PO before meals; (2) Metformin (250mg/tablet), 1T TID, PO after meals.

\section{Student Surveys}

Questionnaire surveys were carried out in 2015, 2016 and 2017. Survey were conducted in 4 parts to assess effectiveness of the clinical pharmacy training modules as mentioned above and students' knowledge and skills after its completion. Informed consent was obtained from all students. Firstly, a questionnaire was designed to assess students' general perception and satisfaction regarding clinical pharmacy training program with responses given using a 5 -point Likert scale ( $1=$ strongly disagree to $5=$ strongly agree). Then, another questionnaire was designed to evaluate their views on the four main clinical pharmacy training modules such as physical assessment, CPR, MI service and patient education service and the students scored them from 5 to 1 (Full mark was 5). A pre- and post-training questionnaire was also filled by the students to assess students' skills for clinical pharmacy training as mentioned above before and after the training. To avoid the influence of external factors, the questions on the pre- and post-training were the same.

Analysis of the quantitative data was performed using Microsoft Excel for Windows 8 and IBM SPSS version19 statistical software. Wilcoxon rank-sum test was used for analysis of pre-and post- training. A $p$ value of 0.05 was considered to be significant. The calculation of the mean score in the satisfaction survey was based on 5-point from 5 to 1 .

\section{RESULTS}

One hundred and seventy-nine students participated in these training. Data for 170 students was analyzed, because seven students filled the questionnaire incompletely (response rate $94.9 \%$ ). Majority of the respondents were female $(80.0 \%, 136 / 170)$, with the mean age of 22.2 years $(\mathrm{SD}=0.78)$.

The results of students' perception on clinical pharmacy training are presented in Table 2. Most students showed good response regarding clinical pharmacy training, $97 \%$ of students agreed or strongly agreed that training could promote the integration of theory with practice. Almost all the students (98\%) thought that clinical pharmacy training helped in improving practical skills. Furthermore, $94 \%$ of students showed interest in learning by clinical pharmacy training. More than $90 \%$ students preferred training-based learning over traditional teaching methods. $79 \%$ of students felt that clinical pharmacy training helped boosting confidence.

The results of questionnaire evaluating the 4 training modules are showed in Table 3. Through physical examination training, students $(87 \%)$ believed that they can have more vivid understanding of the methods of physical examination and most students (86\%) agreed or strongly agreed physical examination training contributes in carrying out effective clinical pharmacy services. Almost all the students (97\%) agreed or strongly agreed that the combination of teaching and practice can help them master the skills of CPR. It will be helpful for their future working as professional clinical 
Table 2: The Results of Students' Views on Clinical Pharmacy Training ( $\mathrm{N}=170)$.

\begin{tabular}{|c|c|c|c|c|c|}
\hline Question Item & $\begin{array}{c}\text { Strongly } \\
\text { Disagree } \\
\text { No. (\%) }\end{array}$ & $\begin{array}{c}\text { Disagree } \\
\text { No. (\%) }\end{array}$ & $\begin{array}{l}\text { Neutral } \\
\text { No. (\%) }\end{array}$ & $\begin{array}{l}\text { Agree } \\
\text { No. (\%) }\end{array}$ & $\begin{array}{c}\text { Strongly } \\
\text { Agree } \\
\text { No. (\%) }\end{array}$ \\
\hline $\begin{array}{c}\text { Clinical pharmacy training can promote the integration of theory with } \\
\text { practice. }\end{array}$ & 0 & 0 & $5(3)$ & $56(33)$ & $109(64)$ \\
\hline Clinical pharmacy training helps to improve practical skills. & 0 & 0 & $3(2)$ & $69(40)$ & $98(58)$ \\
\hline Clinical pharmacy training helps to increase interest in learning. & 0 & 0 & $10(6)$ & $73(43)$ & $87(51)$ \\
\hline $\begin{array}{c}\text { Clinical pharmacy training helps to understand clinical pharmacy } \\
\text { services. }\end{array}$ & 0 & 0 & $6(3)$ & $66(39)$ & $98(58)$ \\
\hline $\begin{array}{l}\text { Compared with traditional teaching methods, I prefer clinical pharmacy } \\
\text { training courses. }\end{array}$ & 0 & 0 & $10(6)$ & $64(38)$ & $96(56)$ \\
\hline $\begin{array}{l}\text { I have more confidence in internship or working after completing } \\
\text { clinical pharmacy training. }\end{array}$ & 0 & $2(1)$ & $34(20)$ & $87(51)$ & $47(28)$ \\
\hline
\end{tabular}

\begin{tabular}{|c|c|c|c|c|c|}
\hline Question Item & $\begin{array}{l}\text { Strongly } \\
\text { Disagree } \\
\text { No. (\%) }\end{array}$ & $\begin{array}{c}\text { Disagree } \\
\text { No. (\%) }\end{array}$ & $\begin{array}{l}\text { Neutral } \\
\text { No. (\%) }\end{array}$ & $\begin{array}{l}\text { Agree } \\
\text { No. (\%) }\end{array}$ & $\begin{array}{l}\text { Strongly } \\
\text { Agree } \\
\text { No. (\%) }\end{array}$ \\
\hline $\begin{array}{l}\text { I can have more vivid understanding of the methods of physical } \\
\text { examination by training. }\end{array}$ & 0 & $2(1)$ & $20(12)$ & $91(54)$ & $57(33)$ \\
\hline $\begin{array}{l}\text { I think physical examination training contributes in provision of } \\
\text { effective clinical pharmacy services. }\end{array}$ & $1(1)$ & $1(1)$ & $21(12)$ & $73(43)$ & $74(43)$ \\
\hline $\begin{array}{c}\text { Use of simulated patients can help me understand the rescue } \\
\text { process and drugs used in CPR. }\end{array}$ & 0 & $1(1)$ & $11(6)$ & $68(40)$ & $90(53)$ \\
\hline $\begin{array}{l}\text { The combination of teaching and practice is helpful to master the } \\
\text { skills required for CPR. }\end{array}$ & 0 & 0 & $6(3)$ & $52(32)$ & $110(65)$ \\
\hline $\begin{array}{l}\text { CPR training can facilitate my future working as a clinical } \\
\text { pharmacist. }\end{array}$ & $2(1)$ & $1(1)$ & $19(11)$ & $69(41)$ & $79(46)$ \\
\hline $\begin{array}{l}\text { Medication information simulation training can help me grasp the } \\
\text { medication information service skills. }\end{array}$ & 0 & $2(1)$ & $18(11)$ & $82(48)$ & $68(40)$ \\
\hline $\begin{array}{l}\text { Compared with traditional teaching methods, medication } \\
\text { information service training is more effective for acquiring } \\
\text { knowledge and skills. }\end{array}$ & $4(2)$ & $5(3)$ & $14(8)$ & $68(40)$ & $79(47)$ \\
\hline $\begin{array}{l}\text { I can identify lacking in my theoretical knowledge and practical } \\
\text { ability by patient education training (role-playing). }\end{array}$ & 0 & 0 & $3(2)$ & $53(31)$ & $114(67)$ \\
\hline $\begin{array}{l}\text { Compared with traditional teaching methods, patient education } \\
\text { training can assist me gain more knowledge and skills. }\end{array}$ & $2(1)$ & $3(2)$ & $27(14)$ & $60(31)$ & $98(52)$ \\
\hline
\end{tabular}

pharmacists (89\%). For MI service training, $88.0 \%$ of students thought that simulation training model could help grasp the MI service skills. Almost all the students $(98 \%)$ agreed or strongly agreed that they could identify their lacking between theoretical knowledge and practical ability by patient education service training (role-play) and they $(93 \%)$ gained more knowledge and skills through this training.

The results of scoring for the trainings are illustrated in Figure 3. The mean score of physical assessment training was $4.22(\mathrm{SD}=0.78)$. Most students $(84 \%)$ scored 4 and 5 point, only one student had given 1 scores. For CPR training, the mean score was $4.75(\mathrm{SD}=0.55), 81 \%$ of students gave 5 points. The mean score of MI service training was $4.51(\mathrm{SD}=0.66)$ and more than half of the students $(60 \%)$ had given 5 points. The mean score of patient education service training was $4.81(\mathrm{SD}=0.47)$, $84 \%$ of the students scored 5 point and no one scored 1 or 2 points.

In order to evaluate effectiveness of the training, we conducted a questionnaire survey before and after the training (Table 4, 5). A Wilcoxon rank-sum test was performed to compare the skills related to physical examination training, CPR training, MI service training and patient education service training. Comparisons for all items showed students' understanding significantly improved after training $(p<0.001)$. Most of the students thought that their skills were improved after training 

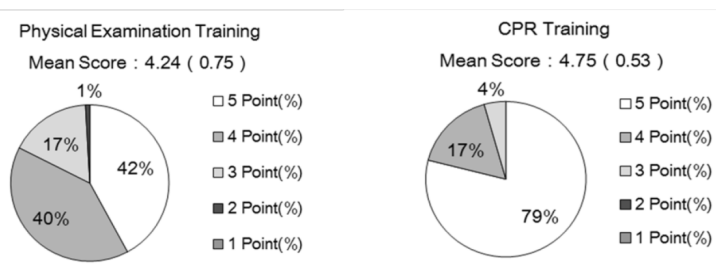

MI Service Training

Mean Score : 4.45 ( 0.66 )
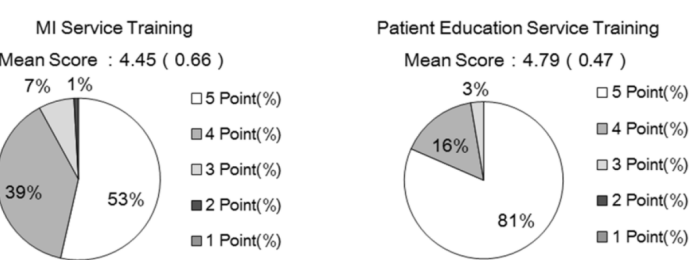

Figure 3: Score Statistics for Four Main Clinical Pharmacy Training.

Figure legends: Figure 3 shows the score of physical assessment, CPR, MI service and patient education service and the percentages of each point. This figure represents the satisfactions of to physical assessment, CPR, MI service and patient education service.

\begin{tabular}{|c|c|}
\hline No. & Question Item \\
\hline 1 & $\begin{array}{l}\text { I master the methods of measuring vital signs by physical } \\
\text { examination training. }\end{array}$ \\
\hline 2 & $\begin{array}{l}\text { I can use diagnostic examination tools (e.g. } \\
\text { stethoscopes, sphygmomanometer, etc.) }\end{array}$ \\
\hline 3 & $\begin{array}{l}\text { I master the basic skills of CPR and can use those skills } \\
\text { practically. }\end{array}$ \\
\hline 4 & $\begin{array}{l}\text { I can carry out medication information service } \\
\text { independently. }\end{array}$ \\
\hline 5 & I master basic skills of providing medication instruction. \\
\hline 6 & $\begin{array}{l}\text { I have the ability to communicate with patients } \\
\text { reasonably and master the communication skills with } \\
\text { patients. }\end{array}$ \\
\hline
\end{tabular}

\begin{tabular}{|c|c|c|c|c|c|c|c|c|c|c|c|}
\hline \multicolumn{8}{|c|}{ Table 5: Comparison of the Questionnaire between Pre- and Post-training (N=170). } \\
\hline \multirow{2}{*}{$\begin{array}{c}\text { Question } \\
\text { No. }\end{array}$} & \multicolumn{4}{|c|}{ Pre-training (Number of student) } & \multicolumn{5}{c|}{ Post-training (Number of student) } \\
\hline & Excellent & Good & Neutral & Poor & Worse & Excellent & Good & Neutral & Poor & Worse & $p^{\text {a }}$ \\
\hline 1 & 2 & 25 & 71 & 50 & 22 & 40 & 78 & 43 & 6 & 3 & $p<0.001$ \\
\hline 2 & 1 & 26 & 63 & 48 & 32 & 36 & 72 & 52 & 8 & 2 & $p<0.001$ \\
\hline 3 & 2 & 20 & 60 & 55 & 33 & 59 & 69 & 25 & 11 & 6 & $p<0.001$ \\
\hline 4 & 4 & 13 & 38 & 77 & 38 & 32 & 57 & 52 & 24 & 5 & $p<0.001$ \\
\hline 5 & 3 & 9 & 53 & 75 & 30 & 44 & 90 & 32 & 3 & 1 & $p<0.001$ \\
\hline 6 & 3 & 27 & 93 & 40 & 7 & 46 & 74 & 26 & 10 & 14 & $p<0.001$ \\
\hline
\end{tabular}

a: Comparisons for all items showed students' skills improved after training, $p<0.001$ (Wilcoxon rank-sum test).

and they were more confident in providing clinical pharmacy services.

\section{DISCUSSION}

Clinical pharmacy training program established in CPU in 2015 and it is the first comprehensive training model for Bachelors (clinical pharmacy students) in China. The aim of this training is to help students master the skills of clinical pharmacy services and increase students' confidence in their ability to perform clinical roles effectively. In this study, we identified some advantages and disadvantages of this training through students' feedback. Most students indicated that the training courses and the modules increased their interest in learning. They could find deficiencies in practice through training. In case of physical examination, students felt that learning the measurement of vital signs by High Fidelity Patient Simulator "Stan ${ }^{\circledR}$ " was easier and understandable. Students showed high satisfaction to CPR training, because everyone had practically performed CPR by simulators. Additionally, teachers' and simulators corrected and guided students on every step. They showed agreement to MI training, as it helped them learn about processing and retrieving appropriate information to solve specific medication problem. Patient education service training helped students improve their communication skills by role-play and deepened their understanding for treatment with diabetes, hypertension and hyperlipidemia. Although we successfully carried out the training programs, there were some deficiencies: (1) not all training sessions had "practice time" as the limitation of time and equipment, like PIVAS training. (2) Time period was too short to completely master the skills we teach. (3) The training module might not well-established, rational use of medicines including rational use of antibiotics should be taken into account. (4) Evaluation system adopted for assessing students' competencies in clinical pharmacy training cannot be considered an ultimate or absolute tool. (5) We asked students for self-evaluation that may slightly influence the results. 
Researchers suggest that prolonging the time of training, increasing contact-hours, giving more scenarios to practice rational use of medicines and increasing the proportion of the simulation time can be more effective for enhancing students learning. More chances could be created for students to solve more medication-related questions in MI service training. In CPR training, the simulation of drug therapy could be more varied. Colleges should increase the quantity of scenarios and make every student play as pharmacist in patient education service training.

We have also searched various databases to identify studies that have employed any suitable evaluation system for assessing students' competencies. In United States, United Kingdom and other countries, objective structured clinical examination (OSCE) was used in schools and colleges of pharmacy and researchers had confirmed its important role in assessment of clinical competence of pharmacy students. ${ }^{26-29}$ This approach was introduced by Dr. Ronald M. Harden in $1975 .{ }^{30}$ However, OSCE has been recently introduced in pharmacy education and it is still not well understood and implemented in various countries including Chinese schools and colleges. But it seems to be promising especially if it is combined with the clinical simulation training.

Limitation of this study was that we did not score all training courses. Secondly, the training module might not well-established, standardized patients weren't used in patient education service training and rational use of medicines should be included in our training. Another limitation was that we didn't establish suitable evaluation system, so in students' skills of clinical pharmacy service survey, we made students conduct self-evaluation, it may influence the results.

\section{CONCLUSION}

Clinical pharmacy training program can increase students' interest in learning and improve their practical abilities. Besides, the training program has increased students' confidence in internship experience. It is more effective and feasible teaching method as compared to hospital or clinical orientation. Colleges have set up a reasonable clinical pharmacy training curriculum and process, but they don't have appropriate evaluation system. OSCE should be used and promoted in accessing efficacy of clinical pharmacy training programs.

\section{ACKNOWLEDGEMENT}

Authors express deep gratitude to academicians in CPU for their support in preparing clinical pharmacy training and all the students providing their time for filling questionnaires for the current study.

\section{CONFLICT OF INTEREST}

The authors declare that they have no conflicts of interest.

\section{ABBREVIATIONS}

ACPE: Accreditation Council for Pharmacy Education; IPPEs: Introductory Pharmacy Practice Experiences; CPU: China Pharmaceutical University; BS: Bachelor of Science; PBL: Problem-based Learning; CPR: Cardiopulmonary Resuscitation; MI: Medication Information; COPD: Chronic Obstructive Pulmonary Disease; PIVAS: Pharmacy Intravenous Admixture Services; TDM: Therapeutic Drug Monitoring; FPG: Fasting plasma glucose; PPG: Postprandial blood glucose; TID: Ter In Die; PO: Peros; SD: Standard Deviation; OSCE: Objective structured clinical examination.

\section{REFERENCES}

1. Fernandez R, Parker D, Kalus JS, Miller D, Compton S. Using a human patient simulation mannequin to teach interdisciplinary team skills to pharmacy students. American Journal of Pharmaceutical Education. 2007;71(3):51.

2. Accreditation Council for Pharmacy Education. Accreditation standards and guidelines for the professional program in pharmacy leading to the doctor of pharmacy degree [guidelines on the Internet]. Chicago: The Accreditation Council; c2011 [updated 2011 Jan 23; cited 2016 Oct 17]. [about 36 p.]. Available from: https://www.acpe-accredit.org/pdf/FinalS2007 Guidelines2.0.pdf.

3. Accreditation Council for Pharmacy Education. Guidance for the accreditation standards and key elements for the professional program in pharmacy leading to the doctor of pharmacy degree [guidelines on the Internet]. Chicago: The Accreditation Council; c2015 [updated 2015 Jan 25; cited 2016 Oct 17]. [about 17 p.]. Available from: https://www.acpe-accredit.org/pdf/ Standards2016FINAL.pdf.

4. Leon N, Hajjar E, DeSevoBellottie G. Sequencing of simulation and clinic experiences in an introductory pharmacy practice experience. American Journal of Pharmaceutical Education. 2015;79(8):120.

5. McGaghie WC, Issenberg SB, Petrusa ER, Scalese RJ. Revisiting' a critical review of simulation-based medical education research: 2003-2009. Medical Education. 2016;50(10):986-91.

6. Abas T, Juma FZ. Benefits of simulation training in medical education. Advances in Medical Education and Practice. 2016;18(7):399-400.

7. Warren JN, Luctkar-Flude M, Godfrey C, Lukewich J. A systematic review of the effectiveness of simulation-based education on satisfaction and learning outcomes in nurse practitioner programs. Nurse Education Today. 2016;46:99-108.

8. Neorich Co. Ltd of Japan [homepage on the Internet]. Tokyo: Neorich. Co. Ltd.; c2007 [cited 2016 Oct 20]. Available from: http://yakkei.com.

9. Tokunaga J, TakamuraN, Ogata K, Yoshida H, Totoribe K, Nagata M, et al. Medical emergency education using emergency care simulators in the school of pharmaceutical sciences. Yakugaku Zasshi Journal of the Pharmaceutical Society of Japan. 2008;128(7):1045-55.

10. Ichikawa A. Pharmaceutical common achievement test: computer-based testing. Yakugaku Zasshi Journal of the Pharmaceutical Society of Japan. 2007;127(6):941-945. 
11. Vyas D, Bray BS, Wilson MN. Use of simulation-based teaching methodologies in US colleges and schools of pharmacy. American Journal of Pharmaceutical Education. 2013;77(3):53.

12. Vyas D, Wombwell E, Russell E, Caligiuri F. High-fidelity patient simulation series to supplement introductory pharmacy practice experiences. American Journal of Pharmaceutical Education. 2010;74(9):169.

13. Kirwin JL, DiVall MV, Guerra C, Brown T. A simulated hospital pharmacy module using an electronic medical record in a pharmaceutical care skills laboratory course. American Journal of Pharmaceutical Education. 2013;77(3):62.

14. Kawahara A, Sekino H. Perspectives on educational reform of pharmaceutical science. Yakugaku Zasshi Journal of the Pharmaceutical Society of Japan. 2007;127(6):973-6.

15. The Pharmaceutical Society of Japan. Model Core Curriculum of Pharmacy Practice (Ver1.1, 2006) [monograph on the Internet]. Tokyo: The Pharmaceutical Society; 2006 [cited 2016 Oct 20]. Available from: http://www. pharm.or.jp.

16. Tokunaga J, Takamura N, Ogata K, Yoshida H, Setoguchi N, Matsuoka T, et al. Vital sign monitoring using human patient simulators at pharmacy schools in Japan. American Journal of Pharmaceutical Education. 2010;74(7):132.

17. $\mathrm{Xu} \mathrm{C}$, Naitong $\mathrm{Z}$, Ming $\mathrm{H}$. [Current situation suggestions for clinical pharmacy undergraduate education in China, Chinese]. China Pharmacy. 2015;26(6):858-61.

18. GuihuaY. [Practice of the application of simulated pharmacy, Chinese]. China Pharmacy. 2012;23(8):858-61.

19. Weijian $\mathrm{H}$, Chunxing $\mathrm{L}$, Xian $\mathrm{W}$, Zuliang $\mathrm{H}$. [Application of modern educational technology in PBL teaching in simulated pharmacy, Chinese]. Shizhen Medicine and Materia Medica Research. 2014;25(12):3041-2.

20. Qinghua D, Xiaoying L, Hongyan J, Qingyuan Zh, Aiqi X, Ying X, et al. [Application of simulated pharmacies in cultivating students' professional competence, Chinese]. Chongqing Medicine. 2011;40(32):3325-6.

21. American Heart Association. 2010 American Heart Association Guidelines for Cardiopulmonary Resuscitation and Emergency Cardiovascular Care. Circulation [serial on the Internet]. 2010;122(Suppl3). [cited 2014 May 19] Available from: http://circ.ahajournals.org/content/122/18_suppl_3/S640.full.
22. Expert group of Chinese 2011 cardiopulmonary resuscitation. [Chinese 2011 cardiopulmonary resuscitation expert consensus. Chinese Journal of Cardiovascular Research, Chinese]. 2011;12(9):881-7.

23. National Health Commission of the People's Republic of China. Regulations of Pharmacy Administration in the Medical Institution [homepage on the Internet]. Beijing: The Commission c2018 [updated 2011 Mar 30; cited 2014 May 9]. Available from: http://www.nhfpc.gov.cn/yzygj/ s3593/201103/4119b5de252d45ac916d420e0d30fda7.shtml.

24. The International Pharmaceutical Federation, World Health Organization. Joint FIP/WHO guidelines on good pharmacy practice: standards for quality of pharmacy services [guidelines on the Internet]. Geneva: The WHO; c2011. [updated 2011; cited 2014 May 20]. [about 6 p.]. Available from: http://apps. who.int/medicinedocs/documents/s18676en/s18676en.pdf.

25. National Health Commission of the People's Republic of China.

Prescription Administrative Policy [homepage on the Internet]. Beijing: The Commission c2018 [updated 2007 Mar 13; cited 2014 May 15]. Available from: http://www.gov.cn/flfg/2007-03/13/content_549406.htm.

26. Austin Z, O'Byrne C, Pugsley J, Munoz LQ. Development and validation process for an objective structured clinical examination (OSCE) for entryto-practice certification in pharmacy: the Canadian experience. American Journal of Pharmaceutical Education. 2003;67(3):76.

27. Salinitri FD, O'Connell MB, Gawood CL, Lehr VT, Abdallah K. An objective structured clinical examination to assess problem-based learning. American Journal of Pharmaceutical Education. 2012;76(8):44.

28. Kogo M, Koyama N, Negoro T, Aoki K, Saito I, Kobayashi Y, et al. Analysis of students-achievement rate and contents of assessment for objective structured clinical examination (OSCE) attempted at the faculty of pharmaceutical sciences, Showa University. Yakugaku Zasshi Journal of the Pharmaceutical Society of Japan. 2007;127(5):905-17.

29. Awaisu A, AbdRahman NS, NikMohamed MH, BuxRahman BuSH, Mohamed Nazar NI. Malaysian pharmacy students' assessment of an objective structured clinical examination (OSCE). American Journal of Pharmaceutical Education. 2010;74(2):34.

30. Harden RM. What is an OSCE?. Medical Teacher. 1988;10(1):19-22.

\section{PICTORIAL ABSTRACT}

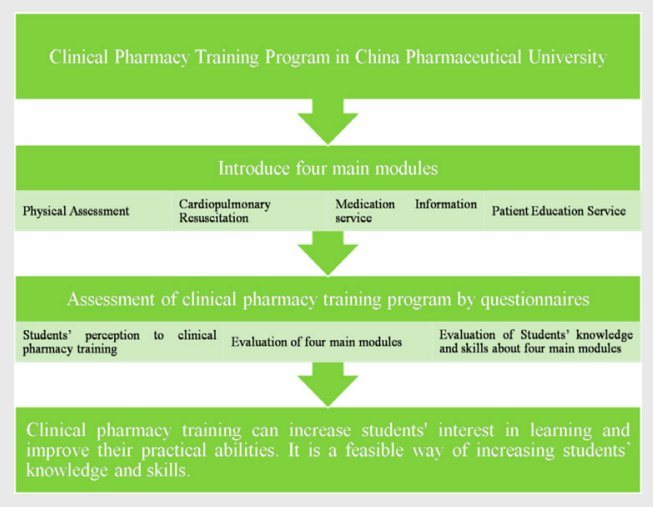

\section{Summary}

- Pharmaceutical education is now oriented more towards problem solving and providing patient care. Development of practical abilities plays increasingly important role in pharmacy education.

- A variety of teaching methods was used to improve pharmacy students' competency of providing pharmacy services.

- In order to meet the requirements of the pharmaceutical education, China Pharmaceutical University had designed a clinical pharmacy training program and carried it out since 2015 .

- Some surveys was designed to evaluate students' perception, understanding and knowledge about this program from 2015 to 2017. Data was analyzed and interpreted using statistical methods.

- Most of the students had a high degree of satisfaction to clinical training. Students' confidence of providing clinical pharmacy services was significant increased after training.

- Clinical pharmacy training can increase students' interest in learning and improve their practical abilities. 


\section{About Authors}

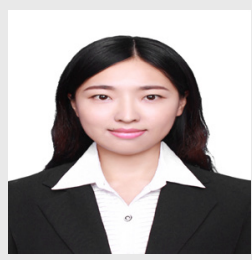

Miss Jiaqi Li: is a clinical pharmacist from Department of Pharmacy, Nanjing Drum Tower Hospital, The Affiliated Hospital of Nanjing University Medical School, Jiangsu, CHINA. Currently, she working in the area of providing clinical pharmaceutical services and researching on pharmacy teaching. The data of the paper are parts of the master thesis in China Pharmaceutical University supervised by professor Yang.

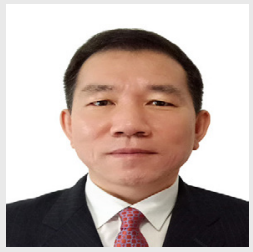

Dr Changqing Yang: is a Professor, Department of Clinical Pharmacy, School of Basic Medicine and Clinical Pharmacy, China Pharmaceutical University, CHINA. He is actively involved in researches of clinical pharmacy and clinical pharmacokinetics, clinical pharmacy education, metabolic pathway of innovative drugs, etc, published more than 80 research papers in various national and international journals. He is also serving as Editorial board member for $\mathrm{J}$. Kor. Soc. Health-syst. Pharm.

Cite this article: Li J, Yang C, Madiha. Establishing and Evaluating Clinical Pharmacy Training Program in China Pharmaceutical University. Indian J of Pharmaceutical Education and Research. 2019;53(1):70-8. 